\title{
Prognostic factors of Atractylis gummifera L. poisoning, Morocco
}

S. Achour, ${ }^{1,2}$ N. Rhalem, ${ }^{2,3}$ S. Elfakir, ${ }^{4}$ A. Khattabi, ${ }^{2,3}$ C. Nejjari, ${ }^{4}$ A. Mokhtari, ${ }^{2}$ A. Soulaymani ${ }^{2}$ and R. Soulaymani ${ }^{3,5}$

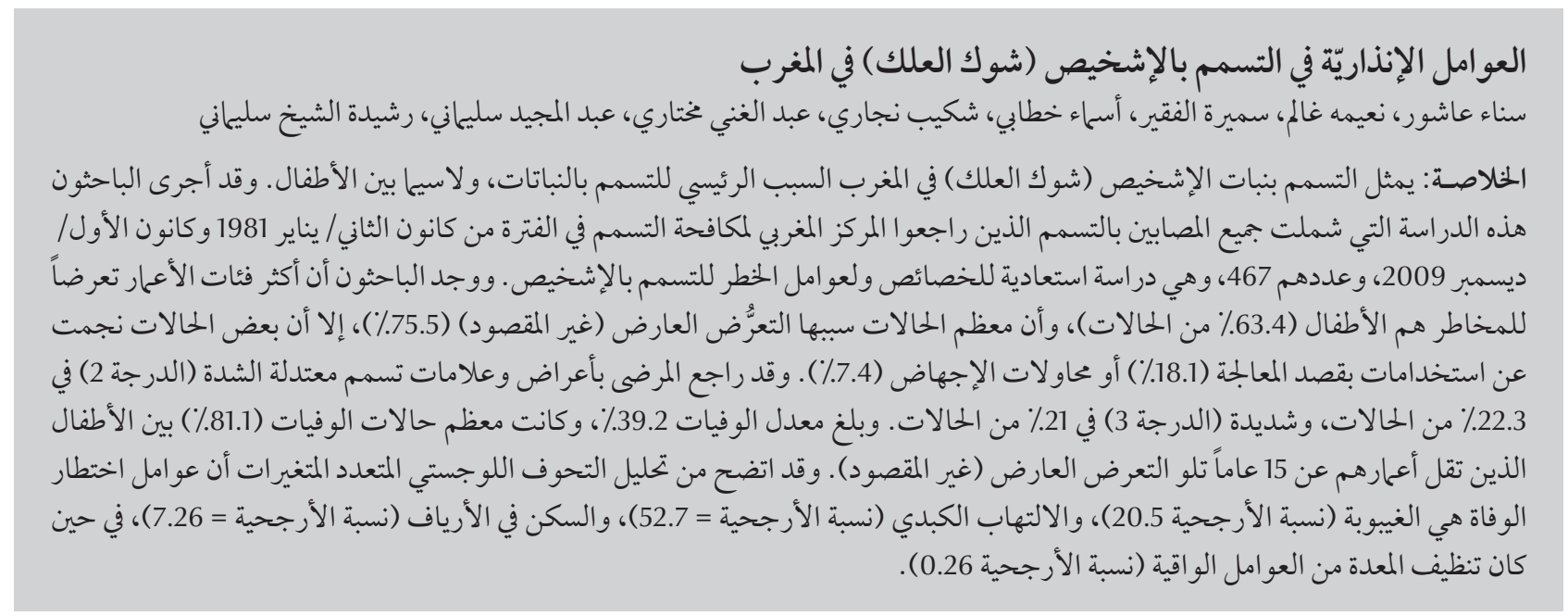

ABSTRACT In Morocco, acute Atractylis gummifera L. poisoning represents the leading cause of death by plant poisoning especially for children. All cases received in the Moroccan poison control centre from January 1981 to December $2009(n=467)$ were included in a retrospective study of the characteristics and risk factors of $A$. gummifera L. poisoning The most vulnerable age group was children (63.4\% of cases). Most cases were due to accidental exposure (75.5\%), but some were from therapeutic use (18.1\%) or attempted abortion (7.4\%). Patients presented with moderate poison severity signs (grade 2 ) in $22.3 \%$ of cases or severe signs (grade 3 ) in $21.0 \%$. The mortality rate was $39.2 \%$. The majority of deaths (81.1\%) occurred in children aged $<15$ years following accidental exposure. Multivariate logistic regression analysis revealed that risk factors for mortality were coma $(O R=20.5)$; hepatitis $(O R=52.7)$ and rural residence $(O R=7.26)$, while gastric decontamination was a protector factor $(O R=0.26)$.

\section{Facteurs pronostiques d'intoxication par Atractylis gummifera L. au Maroc}

RÉSUMÉ Au Maroc, l'intoxication aiguë par Atractylis gummifera L. représente la principale cause de décès dus à une intoxication par les plantes, en particulier chez les enfants. Tous les cas reçus au centre antipoison marocain entre janvier 1981 et décembre $2009(n=467)$ ont été inclus dans une étude rétrospective des caractéristiques et des facteurs de risque d'une intoxication par $A$. gummifera $\mathrm{L}$. Le groupe d'âge le plus vulnérable était les enfants (63,4 \% des cas). La plupart des cas étaient dus à une exposition accidentelle (75,5\%), mais certaines expositions avaient des visées thérapeutiques $(18,1 \%)$ ou abortives $(7,4 \%)$. Les patients présentaient des signes d'intoxication d'une intensité modérée (grade 2) dans 22,3\% des cas, ou d'une intensité sévère (grade 3) dans $21,0 \%$ des cas. Le taux de mortalité était de 39,2\%. La majorité des décès $(81,1 \%)$ se sont produits chez des enfants de moins de 15 ans, à la suite d'une exposition accidentelle. L'analyse de régression logistique multivariée a révélé que les facteurs de risque de mortalité étaient un coma (O.R. $=20,5)$, une hépatite $(O . R .=52,7)$ et la résidence en milieu rural $(O . R .=7,26)$, tandis qu'une décontamination gastrique constituait un facteur protecteur $($ O.R. $=0,26)$. 


\section{Introduction}

Atractylis gummifera L. also called "glue thistle" or "addad" is a poisonous plant widespread in North Africa (Tunisia, Morocco, Algeria), Asia Minor and southern Europe (Spain, Portugal, Italy, Greece), but also in France (Corsica) [1]. This thistle, accidentally injested or used in traditional medicines, causes serious poisoning incidents with fatal outcome in many cases, and constitutes a public health problem especially for children in the Mediterranean region [2]. Victims of intoxication are mainly rural children, who confuse the root with other edible plants, such as the artichoke Scolymus hispanicus L., or use the white substance, which it exudes as chewing gum. Intoxication can also occur during use of the glue thistle as a medicinal plant because of its antipyretic, diuretic, abortifacient, emetic and purgative properties [3].

The toxic effect of this plant arises from 2 diterpenoid toxicants causing toxicity-atractyloside and carboxyatractyloside - which are a powerful mitochondrial inhibitors of oxidative phosphorylation and interact with a mitochondrial protein involved in mitochondrial membrane permeabilization. This action is exerted especially in cells rich in mitochondria such as hepatocytes and in proximal tubular epithelial cells. The consequences are cell necrosis with extensive liver damage and kidney failure. Poisoned patients manifest characteristic symptoms such as nausea, vomiting, epigastric and abdominal pain, diarrhoea, hepatitis, anxiety, headache and convulsions, often followed by coma. No specific pharmacological treatment for A. gummifera intoxication is yet available and all the current therapeutic approaches are only symptomatic.

In Morocco, poisoning by this plant is very common and frequently fatal $[4,5]$ and represents the leading cause of death by plant poisoning in Morocco
[6]. The thistle is available in herbal stalls and markets and is frequently found in nature in the wild, except in desert areas or dry lands and the Anti-Atlas mountains [7]. From 1980 to 2008, the poison control centre of Morocco has collected 4287 cases of poisoning by plants, of which death occurred in $7.3 \%$. The glue thistle was implicated in $77.6 \%$ of these deaths [6].

Published data about A. gummifera L. poisoning are rare and limited to a few clinical cases. A comprehensive study with a determination of risk factors has never been made. The current study aimed to evaluate a series of cases of acute A. gummifera L. poisoning in the Moroccan population to determine the characteristics and the prognostic factors of this type of poisoning in our context.

\section{Methods}

\section{Study population and data collection}

The present retrospective study was performed in Morocco. All cases related to acute A. gummifera L. poisoning received in the Moroccan poison control centre from January 1981 to December 2009 were included.

The survey collected information on sociodemographic characteristics (age, sex, origin), circumstances (accident, therapeutic use, suicide), clinical symptoms, therapeutic aspects (symptomatic treatment and gastric decontamination) and outcome (mortality rate). The patient's clinical state was classified according to the Poisoning Severity Score [8]. Treatment at the centre is based on symptomatic treatment such as the correction of hypoglycaemia by infusion of glucose solution, the administration of oxygen or intubationventilation in case of respiratory or neurological distress and correction of metabolic acidosis and hydroelectrolyte disorders.

\section{Statistical analysis}

Epi 2000, version 3.3.2 program was used to perform the analysis. The chi-squared test was used to assess the significance of differences in the distribution of selected sociodemographic characteristics, circumstances, clinical symptoms, therapeutic aspects and frequency of deaths among the participants.

A logistic regression was performed with death versus living as the dependent variable. We compared the groups of survivors and deceased to determine some prognostic factors. The explanatory factors were coma, hepatitis, gastric decontamination, and residence area. Odds ratios (OR) with $95 \%$ confidence interval (CI) and degree of significance ( $P$-value) was determined for each variable. A $P$-value of $<0.05$ was considered significant.

\section{Results}

In our study 467 cases of A. gummifera L. poisoning were included, representing $10.6 \%$ of all cases of plant poisoning collected over the same period. Declarations came from health professionals in $94.4 \%$ of cases and from the public in $5.6 \%$.

\section{Profile of poisoning cases}

Although the number of cases fluctuated annually, they decreased slightly after 2006 (Figure 1). The number varied between 2 cases in 1982 to 53 cases in 1996 (11.1\%). This type of poisoning was found in all regions of our country with a clear predominance in the region of Fez-Boulemane (27.4\% of cases), followed by the regions of TazaAl Hoceima-Taounate (16.3\%) and Marrakech-Tensift-Al Haouz (10.2\%).

The mean age of cases was 15.3 (SD 12.5) years, ranging from 1 to 70 years. The most vulnerable age group was children (63.4\% of cases), followed by adults (22.4\%). Children aged $4-10$ years and from rural areas were more of 


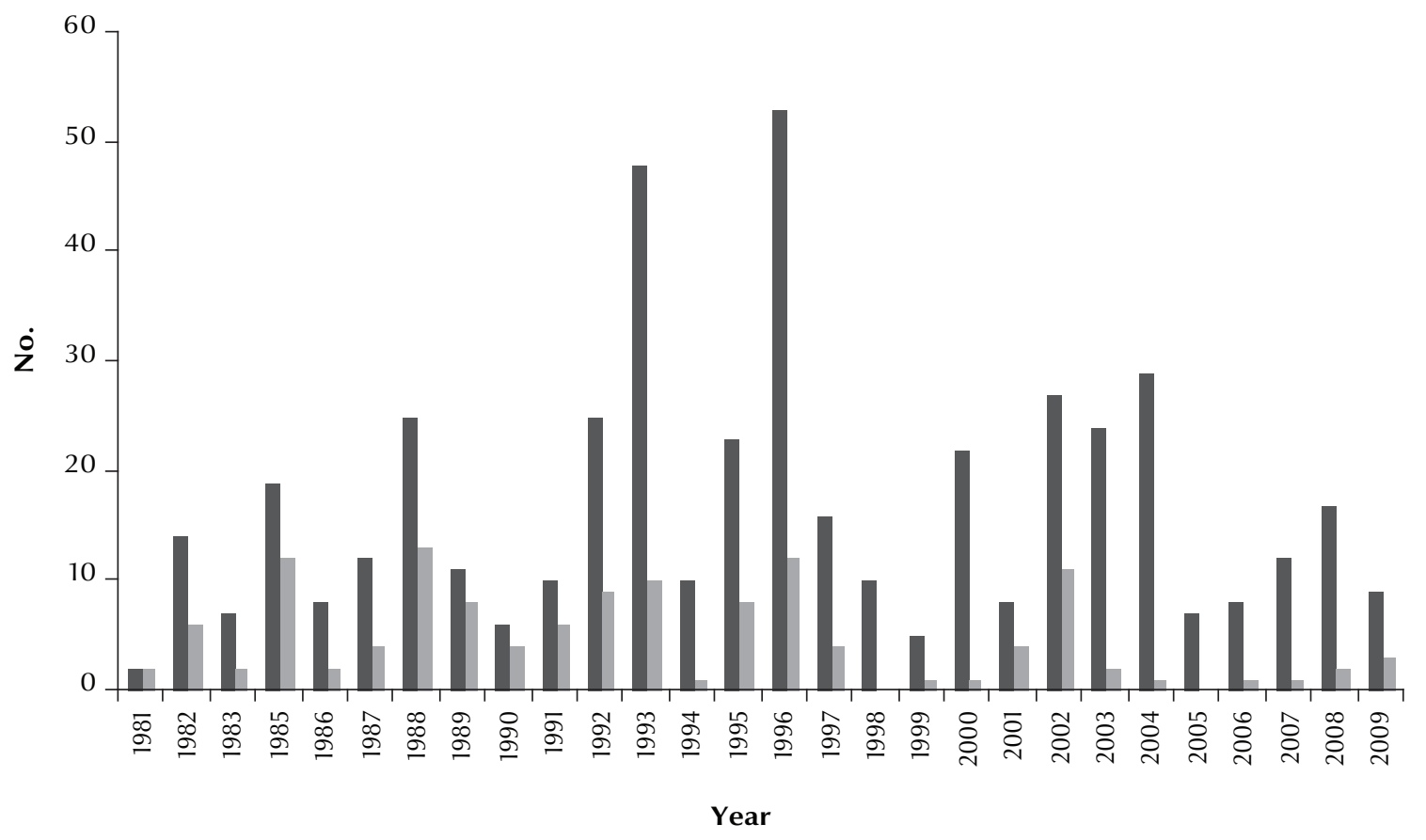

Figure 1 Distribution of cases of poisoning $(n=467)$ and deaths $(n=130)$ due to Atractylis gummifera L. by year $(1981-2009)$

the cases (51.7\%). The sex ratio (male/ female) was 0.76 in favour of females (203 males versus 264 females).

The route of intoxication was indicated in 380 cases. Ingestion was the most common route of exposure (98.0\%), followed by topical administration in only $2.0 \%$ of cases. Accidental exposure was the most common circumstance $(75.5 \%)$; therapeutic use was noted in $18.1 \%$ and the plant was used for attempted abortion in $7.4 \%$. Adult females were more implicated in therapeutic use (48.4\%) and male children in accidental exposure (51.6\%).

Patients were symptomatic in $67.3 \%$ of cases; the evaluation of clinical severity at admission according to Poisoning Severity Score showed that 22.3\% were in grade 2 with pronounced signs and $21.0 \%$ of patients were in grade 3 with life-threatening symptoms. Hepatodigestive disorders were the most commonly observed symptoms (57.0\%) followed by neurological disorders (26.9\%) (Table 1). Hepatitis was found in 106 cases, associated with jaundice and elevation of serum transaminases and bilirubin. Prothrombin time was specified in $61.1 \%$ of cases and it was less than 50\% in 96 cases, while fulminant hepatitis was described at admission in 36 cases. Furthermore, hyperglycaemia followed by hypoglycaemia was reported in $30.3 \%$ of cases and renal failure in $16.2 \%$ of cases.

The management delay after intoxication was less $\leq 4$ hours in $72.2 \%$ of the cases. Gastric decontamination was performed in $40.3 \%$ of cases and symptomatic treatment was made in $71.1 \%$ of cases. The outcome was specified in 332 cases, of which 130 deaths were recorded. The mortality rate was $39.2 \%$. The majority of deaths $(81.1 \%)$ occurred in children aged $<15$ years following accidental exposure. The distribution of cases and deaths according to year is shown in Figure 1. The number of deaths varied in each year with a pronounced decrease after 2002.

\section{Risk factors associated with death}

In order to identify clinical risk factors associated with death, we compared the 2 groups (survivors and deaths) using univariate analysis. The parameters statistically associated with death and elucidated by $P$-value $<0.05$ are reported in Table 2 . Death was significantly more common in children aged $<15$ years $(P<0.001)$, among females $(P=0.05)$, rural residents $(P$ $<0.001)$ and in cases of accidental poisoning $(P<0.001)$. Death was significantly associated with presence of tachycardia, dizziness, miosis, haemorrhage/bleeding, history of hepatitis or coma. Patients with abdominal pain and having gastric decontamination were significantly less likely to die.

Table 3 gives the adjusted OR from multivariate logistic regression models to tease out the adjusted association between different characteristics and survival status. The analysis revealed that a history of coma was 


\begin{tabular}{|c|c|c|}
\hline Signs and symptoms & No. with signs ${ }^{a}$ & $\%$ \\
\hline \multicolumn{3}{|l|}{ Hepato-digestives disorders } \\
\hline Hepatitis & 106 & 12.6 \\
\hline Vomiting & 150 & 17.9 \\
\hline Nausea & 88 & 10.5 \\
\hline Abdominal pain & 73 & 8.8 \\
\hline Intestinal bleeding & 38 & 4.5 \\
\hline Diarrhoea & 24 & 2.9 \\
\hline Total & 479 & 57.0 \\
\hline \multicolumn{3}{|l|}{ Neurological disorders } \\
\hline Coma & 76 & 9.1 \\
\hline Dizziness & 32 & 3.8 \\
\hline Headache & 30 & 3.6 \\
\hline Mydriasis & 26 & 3.1 \\
\hline Sensorymotor deficit & 18 & 2.1 \\
\hline Drowsiness & 16 & 1.9 \\
\hline Convulsions & 14 & 1.7 \\
\hline Restlessness & 14 & 1.7 \\
\hline Total & 226 & 26.9 \\
\hline \multicolumn{3}{|c|}{ Cardio-respiratory disorders } \\
\hline Dyspnoea & 40 & 4.8 \\
\hline Collapse: hypotension & 34 & 4.1 \\
\hline Hypertension & 10 & 1.2 \\
\hline Arrhythmia & 6 & 0.7 \\
\hline Bronchospasm & 3 & 0.3 \\
\hline Apnoea & 2 & 0.2 \\
\hline Cyanosis & 2 & 0.2 \\
\hline Total & 97 & 11.5 \\
\hline \multicolumn{3}{|l|}{ General signs } \\
\hline Anuria & 11 & 1.3 \\
\hline Dry mouth & 9 & 1.1 \\
\hline Sialorrhoea & 8 & 1.0 \\
\hline Asthaenia & 7 & 0.8 \\
\hline Skin rash & 3 & 0.4 \\
\hline Total & 38 & 4.5 \\
\hline All signs & 840 & 100.0 \\
\hline
\end{tabular}

${ }^{a}$ Each patient may have presented 1 or more clinical signs, and therefore the number of symptoms exceeded the number of patients.

significantly associated with higher risk of death compared with the subjects without a history of coma ( $\mathrm{OR}=20.5,95 \%$ CI: 5.0-84.0), independent of the potential confounders. Subjects with a history of hepatitis had a greater likelihood of death than those without $(\mathrm{OR}=52.7,95 \% \mathrm{CI}$ : 15.0-185). Living in a rural area (OR $=7.26,95 \%$ CI: $2.68-19.6)$ was also a risk factor for death. Gastric decontamination was the only protector factor of death $(\mathrm{OR}=0.26,95 \% \mathrm{CI}$ : 0.07-0.96).

\section{Discussion}

Despite the plant's well-known toxicity, ingestion of A. gummifera L continues to be a common cause of poisoning in Morocco. In our study 467 cases were compiled, mainly in the Fez-Boulemane and the Taza-Al Hoceima-Taounate regions. This number is likely to be an underestimate because a large number of patients who died were not declared to the poison centre. Poisoning by this plant is common in the Mediterranean region and frequently fatal. It has been described since the mid-19th century [9]. About 200 cases have been reported since then $[4,10]$, mainly by accidental substitutions or due to children chewing the sweet gum obtained from the latex of its subterranean parts. Although most poisoning cases occur in North Africa [10] they have also been reported among European countries: Greece [11]; Spain [12]; Italy [13]. If used internally it is extremely toxic, even at very low doses.

A report by Hamouda et al. stated that from 1983 to 1998 the Tunisian poisoning centre collected 56 medical records of patients admitted to the toxicological intensive care unit for poisoning with 11 species of plants [14]. The principal plants involved were A. gummifera ( 18 cases; $32 \%)$, Datura stramonium L. (14 cases; 25\%) and Ricinus communis $\mathrm{L}$. ( 5 cases; 9\%). Of these 56 cases 16 were lethal and all of them involving A. gummifera.

Because A. gummifera L. is easily confused with a wild artichoke Scolymus hispanicus L., most poisonings are unintentional ( $75.5 \%$ in our study) and involved mainly children because this thistle has sweet-tasting juice and children enjoy chewing the chewinggum-like substance from the roots [15]. Therapeutic circumstances were reported in $18.1 \%$ and attempted 


\begin{tabular}{|c|c|c|c|c|c|}
\hline \multirow[t]{2}{*}{ Variables } & \multicolumn{2}{|c|}{ Survived } & \multicolumn{2}{|c|}{ Died } & \multirow[t]{2}{*}{$P$-value } \\
\hline & No. & $\%$ & No. & $\%$ & \\
\hline \multicolumn{6}{|c|}{ Demographic data } \\
\hline \multicolumn{6}{|l|}{ Age group (years) } \\
\hline Child (0-14) & 104 & 53.6 & 109 & 87.9 & \multirow{3}{*}{0.001} \\
\hline Teenager (15-19) & 27 & 13.9 & 6 & 4.8 & \\
\hline Adult (20-74) & 63 & 32.5 & 9 & 7.3 & \\
\hline \multicolumn{6}{|l|}{ Sex } \\
\hline Female & 123 & 63.1 & 65 & 52.4 & \multirow[t]{2}{*}{0.05} \\
\hline Male & 72 & 36.9 & 59 & 47.6 & \\
\hline Residence & & & & & 0.001 \\
\hline Urban & 82 & 72.6 & 26 & 35.1 & \\
\hline Rural & 31 & 27.4 & 48 & 64.9 & \\
\hline \multicolumn{6}{|l|}{ Circumstances } \\
\hline Voluntary & 52 & 27.7 & 6 & 5.1 & \multirow[t]{2}{*}{0.001} \\
\hline Accidental & 136 & 72.3 & 111 & 94.9 & \\
\hline \multicolumn{6}{|c|}{ Clinical signs } \\
\hline \multicolumn{6}{|l|}{ Abdominal pain } \\
\hline No & 152 & 76.7 & 123 & 94.6 & \multirow[t]{2}{*}{0.001} \\
\hline Yes & 46 & 23.2 & 7 & 5.4 & \\
\hline \multicolumn{6}{|l|}{ Tachycardia } \\
\hline No & 188 & 94.9 & 115 & 88.5 & \multirow[t]{2}{*}{0.030} \\
\hline Yes & 10 & 5.1 & 15 & 11.5 & \\
\hline \multicolumn{6}{|l|}{ Dizziness } \\
\hline No & 190 & 96.0 & 114 & 87.7 & \multirow[t]{2}{*}{0.005} \\
\hline Yes & 8 & 4.0 & 16 & 12.3 & \\
\hline \multicolumn{6}{|l|}{ Miosis } \\
\hline No & 195 & 98.5 & 122 & 94.6 & \multirow[t]{2}{*}{0.045} \\
\hline Yes & 3 & 1.5 & 7 & 5.4 & \\
\hline \multicolumn{6}{|l|}{ Coma } \\
\hline No & 190 & 96.0 & 90 & 69.2 & \multirow[t]{2}{*}{0.001} \\
\hline Yes & 8 & 4.0 & 40 & 30.8 & \\
\hline \multicolumn{6}{|c|}{ Haemorrhage/bleeding } \\
\hline No & 197 & 99.5 & 122 & 93.8 & \multirow[t]{2}{*}{0.002} \\
\hline Yes & 1 & 0.5 & 8 & 6.2 & \\
\hline \multicolumn{6}{|l|}{ Hepatitis } \\
\hline No & 182 & 91.9 & 41 & 31.5 & \multirow[t]{2}{*}{0.001} \\
\hline Yes & 16 & 8.1 & 89 & 68.5 & \\
\hline Gastric decontamin & & & & & \\
\hline No & 154 & 77.8 & 115 & 88.5 & 0.014 \\
\hline Yes & 44 & 22.2 & 15 & 11.5 & \\
\hline
\end{tabular}

Data missing in some categories.

abortion in $7.4 \%$ of cases. In fact, in folk medicine, A. gummifera has been used to treat several conditions including intestinal parasites, ulcers, snake-bite poisoning, hydrops and drowsiness.
In traditional Arabic medicine it was used to cauterize abscesses. The plant was also known for its antipyretic, diuretic, purgative and emetic properties [16]. It is also used against parasites in folk veterinary medicine [17]. In the popular medicine of North Africa it is still used to treat syphilitic ulcers, induce abortion and bleach the teeth [18]. 


\begin{tabular}{|c|c|c|c|}
\hline Variables & ORa & $95 \% \mathrm{Cl}$ & $P$-value \\
\hline Coma & 20.5 & $5.0-84.4$ & 0.001 \\
\hline Hepatitis & 52.7 & $15.0-185$ & 0.001 \\
\hline Gastric decontamination & 0.26 & $0.07-0.96$ & 0.04 \\
\hline Rural origin (rural versus urban & 7.26 & $2.68-19.6$ & 0.001 \\
\hline
\end{tabular}

$O R a=$ adjusted odds ratio; $C l=$ confidence interval .

Several case reports of poisoning have been published in the literature and provide useful information on the symptoms and laboratory findings that help to identify victims of $A$. gummifera poisoning. The symptoms begin 6-36 hours after the ingestion of the extract of the A. gummifera rhizome [16]. The signs and symptoms found in our series corroborate those found in the literature already cited. The laboratory findings (marked increased in serum glutamic oxaloacetic transaminase, serum glutamic-pyruvic transaminase and bilirubin) may indicate severe hepatocellular damage and acute renal failure [19]. In our series, hepatitis was present in 106 patients and was associated with a high mortality.

A. gummifera L. poisoning is responsible for a heavy burden of morbidity and mortality and to our knowledge the factors that determined death were never investigated. Our study is the first one to focus on the study of prognostics factors. The multivariate analysis revealed that mortality in A. gummifera L. poisoning correlated with coma and hepatitis and the presence of these signs increased the risk of death. This can be explained by the pathologic action of atractyloside and carboxyatractyloside, which involves inhibition of adenosine diphosphate triphosphate conversion through inhibition of $\mathrm{P} 450$ cytochrome, thus leading to damage of tissues. The organs with the greatest oxygen requirements appear to be especially sensitive to damage; these include the brain and liver.

No specific pharmacological treatment (antidote) is currently available to treat A. gummifera intoxication and all therapeutic approaches including fluid and electrolyte replacement, cardiovascular and respiratory support, seizure control and conventional therapeutic methods for severe hepatic and renal failure are only symptomatic [20]. Some authors recommend that standard therapeutic practice should include induction of vomiting, bowel evacuation, gastric decontamination and administration of activated charcoal $[21]$. The majority of these treatments were performed in our patients, except activated charcoal, because it is not available in our country. In our study, gastric decontamination was a protector factor against death, and indeed, by reducing the toxic load, this type of treatment improves the prognosis of poisoned patients. Symptomatic treatment is still insufficient in patients who have taken quantities theoretically lethal of the poison. In spite of the progress achieved in the fields of toxicology and associated therapy, A. gummifera L. poisoning is still responsible for a high rate of mortality (39.2\% in our study). New therapeutic approaches could come from immunotherapy research: some studies have already tried to produce polyclonal Fab antibody fragments against the toxic components of $A$. gummifera [22].

Competing interests: None declared.

\section{References}

1. Skalli $\mathrm{S}$ et al. L'intoxication par le chardon à glu (Atractylis gummifera L.); à propos d'un cas clinique [Poisoning by Atractylis gummifera L: about one clinical case]. Bulletin de la Société de Pathologie Exotique, 2002, 95:284-286.

2. Madani $\mathrm{N}$ et al. Intoxication par le chardon à glu chez une femme enceinte [Poisoning by glue thistle in a pregnant woman]. Presse Medicale (Paris, France), 2006, 35:1828-1830.

3. Ahid S et al. Atractylis gummifera : de l'intoxication aux méthodes analytiques [Atractylis gummifera: from poisoning to the analytic methods]. Annales de Biologie Clinique, 2012, 70:263-268.

4. Hami $\mathrm{H}$ et al. Intoxication par Atractylis gummifera L. Données du centre antipoison et de pharmacovigilance du Maroc [Poisoning by Atractylis gummifera I. Morocco poison control center data]. Bulletin de la Société de Pathologie Exotique, 2010, 104:53-57.
5. Vallejo JR et al. Atractylis gummifera and Centaurea ornata in the province of Badajoz (Extremadura, Spain). Ethnopharmacological importance and toxicological risk. Journal of Ethnopharmacology, 2009, 126:366-370.

6. Rhalem $\mathrm{N}$ et al. Etude rétrospective des intoxications par les plantes au Maroc : Expérience du Centre Anti Poison et de Pharmacovigilance du Maroc (1980-2008) [A retrospective study of poisoning by plants in Morocco: experience of the poison and pharmacovigilance centre of Morocco (19802008]. Toxicologie Maroc., 2010, 5:5-8.

7. Charnot A. La toxicologie au Maroc [Toxicology in Morocco]. Mémoire de la Société des Sciences Naturelles du Maroc, 1945, XLVII:572-598.

8. Person HE et al. Poisoning severity score. Grading of acute poisoning. Clinical Toxicology, 1998, 36:205-213. 
9. Lefranc E. Étude botanique, chimique et toxicologique sur I'Atractylis gummifera [Botanical, chemical and toxicological studies on Atractylis gummifera]. Bulletin de la Société Botanique de France, 1866, 13:146-157.

10. Hamouda $\mathrm{C}$ et al. Plant poisonings from herbal medication admitted to a Tunisian toxicological intensive care unit, 1983-1998. Veterinary and Human Toxicology, 2000, 42:137-141.

11. Georgiou M et al. Hepatotoxicity due to Atractylis gummifera $\mathrm{L}$. Clinical Toxicology, 1988, 26:487-493.

12. Salas J et al. Intoxicaciones por Atractylis gummifera L. en Badajoz (Espana) [Poisoning by Atractylis gummifera L. in Badajoz (Spain)]. Studia Botanica, 1985, 4:201-204.

13. Santi R, Cascio G. Ricerche farmacologiche sul principio attivo dell'Atractylis gummifera [Pharmacological research on the active ingredient of Atractylis gummifera]. Archivio Italiano di Scienze Farmacologiche, 1955, 5:354.

14. Hamouda $\mathrm{C}$ et al. A review of acute poisoning from Atractylis gummifera L. Veterinary and Human Toxicology, 2004, 46:144-146.

15. Stickel F et al. Hepatotoxicity of botanicals. Public Health Nutrition, 2000, 3:113-124.

16. Capdevielle P, Darraq R. Poisoning by bird-lime thistle. Medecine Tropicale, 1980, 40:137-142.
17. Viegi L et al. A review of plants used in folk veterinary medicine in Italy as basis for a databank. Journal of Ethnopharmacology, 2003, 89:221-244.

18. Larrey D, Pageaux GP. Hepatotoxicity of herbal remedies and mushrooms. Seminars in Liver Disease, 1995, 15:183-188.

19. Masria, W. et al. Intoxication par Atractylis gummifera L : à propos de deux cas cliniques [Poisoning by Atractylis gummifera L: about two clinical cases]. Revue Francophone des Laboratories, 2009, 413, 87-91.

20. Stewart MJ, Steenkamp V. The biochemistry and toxicity of atractyloside: a review. Therapeutic Drug Monitoring, 2000, 22:641-649.

21. Ben Salah N et al. Quelques spécialités de chez nous: intoxications par les plantes, le chloralose et le methanol [Some specialties from us: poisoning by plants, chloralose and methanol]. Memoire Online [online journal] (http://www.samu.org/ JAMU2003/jamu2001/chez\%nous11.htm, accessed 31 July 2013).

22. Danielea C et al. Atractylis gummifera L. poisoning: an ethnopharmacological review. Journal of Ethnopharmacology, 2005, 97:175-181. 